\title{
ПРОДВИЖЕНИИ ИНДИВИДУАЛЬНОГО ПРЕДПРИНИМАТЕЛЬСТВА В ГЛОБАЛЬНОЙ СЕТИ ИНТЕРНЕТА.
}

\author{
Жирнова Дарья Алексеевна \\ Российский Государственного Социального Университета, \\ студент коммуникативного менеджмента, студент бакалавриата.
}

Научный руководитель-

Щетинина Нина Николаевна

Аннотация. В статье рассмотрены варианты продвижения индивидуального предпринимательства(оптовой точки продаж) с целью увеличить финансовую выручку бизнеса. Определена роль в интернет-пиара в продвижение оптовой точки продаж кондитерских изделий. Рассмотрены нюансы работы с интернет-ресурсами И.П. в России.

Ключевые слова: Индивидуальное предпринимательство; оптовая точка продаж; кондитерские изделия; официальный сайт; инструменты маркетинга.

На сегодняшний день интернет сопровождение бизнеса является основой любого продвижения. Причем в век технических инноваций продвижение бизнеса в глобальной сети является важным и незаменимым элементом даже для самого малого предприятия или компании. Реальность такова, что потенциальные клиенты ищут в первую очередь информацию в социальных сетях или на официальном сайте фирмы, и если у фирмы чего-то из этого нет то она рискует потерять нового платежеспособного клиента.

Моя диплома работа связанна с организацией медийного сопровождения с помощью создания официального сайта, фирменного стиля и социальных сетей для одной из компаний малого бизнеса. Данный бизнес направлен на оптовую продажу кондитерских изделий разных категорий и сегмента. Фирма, деятельность которой я буду продвигать, является посредником между производителями кондитерских изделий и представителями, а также владельцами коммерческих магазинов, которые в свою очередь будут осуществлять продовольственную деятельность данного товара населению. Конечная цель компании «И.П. Лапин» это получение прибыли, что соответствует «классической» цели любого коммерческого предприятия. Для того чтобы добиться цели, компании необходимо повысить свою узнаваемость на рынке. А для этого компания должна заняться медийным освещением своей работы. Именно поэтому моей целью, является медиа продвижение оптовой точки продажи «И.П. Лапин» для повышения узнаваемости и конечно же увеличение экономической прибыли.

Новизна заключается в том, что работать я буду с компанией индивидуального предпринимательства, а не более крупного бизнеса, а это означает, что я смогу рассмотреть в своем проекте определенные инструменты и механизмы маркетинговых манипуляций, которые подходят именно для этого типа бизнес сферы.

Изначально, индивидуальные предприниматели, владельцы этого бизнеса, не имели никаких аккаунтов в социальных сетях, и вся узнаваемость об их деятельность осуществлялась только методом, так называемого «сарафанного радио». В этом и заключается проблема низких охватов узнаваемости и как следствии продаж. Новые клиенты не могли прийти к этим людям, так как они просто на просто не знали про их существования. А приток клиентов в оптовом бизнесе является залогом успеха.

Все мы слышали фразу «бизнесом правит конкуренция». Но, что есть конкуренция с точки зрения маркетинга? По сути конкуренция это составляющее звено свободы рынка товаров и услуг. Проще говоря, наличие конкурентов, а точнее возможность конкурировать между равными или же почти равными компаниями, дает ощущение полной свободы выбора и свободы действий в отношении этого самого выбора между прямыми клиентами. Стало быть, конкуренция должна быть обязательно. Но, одновременно с этим для бизнесменов встает вопрос и о собственном лидерстве в этой самой конкурентной борьбе. В таком случаи, мы начинаем всерьез задумываться об маркетинговых коммуникациях, так как в нашей современной реальности именно маркетинг занимает главенствующую позицию в любой бизнес среде. И будем максимально откровенны, говоря, что во век, когда потенциальный потребитель избалован и разборчив, маркетингу мы должны уделить весьма большое внимание.

Для достижения данной цели первоначально я решила создать официальный сайт компании.

На сегодняшний день сайт, является лицом любой фирмы, нет сайта-нет лица. Именно поэтому, начинать общение с клиентами стоит со здания официального сайта компании. Именно сайт будет выступать главенствующим информатором о новых событиях компании, об ассортименте продукции, специфики работы и тому подобное. А самое важно, что сайт это всегда один из самых достоверных способов найти контакты организации.

Сайт помогает создать имидж компании. Информация которая подается на сайте способна скоординировать мнение сетевых пользователей и быть их ориентиром в выборе определенного рода продукции. Клиенту не 
придется искать вас на сторонних ресурсах, ведь он всегда сможет взаимодействовать с вами напрямую. Также, напомню, что сайт это максимально удобно для ваших партнеров, поставщиков, спонсоров и прочих коллег. Чем больше сведений вы предоставите, тем большая вероятность, что клиент обратиться именно к вам.

Предприниматели, у которых есть стильный, оптимизированный сайт, всегда более конкурентоспособны.

Но, тут стоит помнить, что сайт сам по себе не приведет к вам новую клиентуру, то есть сайт не есть решение проблемы, но сайт есть отличный, эффективный и уже проверенный инструмент по решению имеющийся проблемы.

При создании сайта, стоит учитывать следующие элементы:

- Практичность (на грамотном сайте все и всегда будет понятно на интуитивном уровне, то есть пользователь не встанет в тупик при желание отыскать прайс-лист или контакты самого предприятия и его прямых представителей) ;

-Дизайн (это то, что привлечет пользователя первоначально. Сайт должен выглядеть привлекательно, чтобы запомнился людям);

-Максимальная визуализация (сегодня реальность такова, что человек воспринимает картинку больше, чем текст. Именно поэтому все что мы хотим сказать, нам необходимо показать, то есть любая информация или во всяком случаи 85\% от нее должна сопровождаться визуальным контентом);

-Креативность (исходя из того, что сегодня онлайн-пользователи крайне избалованы, стоит помнить, что любой сайт должен хоть чем-то удивлять и не быть через чур банальным и обыденным).

Для «И.П. Лапин» я создавала сайт с помощью простой и бесплатной компьютерной программы, а именно с помощью «Wiх».

Тут следует понимать, что даже не большой по масштабам бизнес должен уметь себя представлять, а для этого в первую очередь создается официальный сайт фирмы.

Второй этап работы - это все-таки социальные сети. Для достижения этой цели мной были выбраны следующие действующие на территории Российской Федерации социальные сети: «ВКонтакте» и «Инстаграм». Данные интернет-ресурсы выбраны по принципу популярности и доступности для современных онлайн пользователей, проживающих на территории нашей страны. Ведь, по последним данным в одном лишь «ВКонтакте» зарегистрировано 28155818 человек, что составляет около 30\% числа от «живых» регистраций, то есть это процент реально существующих людей, а не ботов и не бизнес-аккаунтов. Что же касается «Инстаграм», то тут насчитывается 28,3 млн пользователей в России, которые заходят на свою страницу ежедневно и проводят там, как минимум 26 минут в день. Всего же там зарегистрировано 59,4 млн интернетпользователей.

Работая, с этими сетями, я конечно же, отметила для себя их принципиальное отличие. В первую очередь это то, что «Инстаграм» это всегда картинка и лишь иногда немного текстового сопровождения. А вот «ВКонтакте» это уже большая воля для авторства, то есть там и тексты можно публиковать объемнее и видеоматериалы внушительнее. Однако, и там, и там, имеет смысл осуществлять пиар-действия фирмы, которую ты представляешь.

Для успеха компании в социальных сетях я решила прибегнуть одновременно к нескольким методикам. Первоначально это работа с контекстной рекламой. По изученным мной, статистическим данным за 2021 год, контекстный вид рекламы занял $32 \%$ от общего числа всей рекламы в глобальной паутине. Считается, что при правильном подходе, названный вид манипулятивных действий, может привести к быстрому, эффективному и дешевому методу разкрутки бизнеса даже с нуля.

Также одной из прямых задач, для достижения поставленных целей в своем проекте я могу считать создание журналистских материалов, направленных также на поддержание имиджа компании и направленная на то чтобы обратить внимание на наличие того или иного товара у наших предпринимателей.

Тут я начала свой труд именно с таких материалов. Я пошла по нескольким путям. Например, начала с прямых рекламных материалов новых новогодних кондитерских изделий. Такой вариант, возможен только в случаи если мы публикуем материал в преддверии праздников, то есть тогда когда человек активно готовиться к самому главному празднику в году, так как тут мы акцентируем внимание на актуальности событий. Подобные материалы при грамотной техники могут служить неким рычагом давления для подписчиков, что связанно с тем, что мы практически открытым текстом призываем потенциального покупателя пойти и приобрести этот товар. Мы всеми возможными способами начинаем давить на сроки подготовиться к празднованию, которые у нашего читателя уже явно поджимают. Маркетологи утверждают, что это прием давления на «боль» клиента. «Боли» клиента это всегда определенные риски и страхи для наших потенциальных покупателей. В данном случаи это страх не успеть подготовиться к самой главной ночи в году.

Параллельно с этим тут задействован и другой принцип. Речь идет о принципе непосредственной событийности, то есть о том, что мы пользуемся «подходящим» настроением потенциального покупателя. Ведь, не для кого не секрет, что новогоднее настроение в среднем появляется у человека недели за две до самого события. Данный фактор обусловлен прежде всего манипуляциями средств массовой информации и манипуляциями маркетинго-управленческих структур. Первые создают специальные материалы, которые могут 
рассказывать об истории праздника, его приметах, информировать целевую аудиторию о том, как провести длинные зимние выходные. Вторые же добиваются этого эффекта благодаря тематическому оформлению залов, помещений и не только.

В работе SMM же «подогрев» такого настроения всегда играет на пользу. Справедливости раде, добавлю, что в интернет-аккаунтах «И.П. Лапина» я также использую эту технологию. Публикация подходящих статей может оказать не менее благотворное влияние на спрос. Поэтому этот метод я считаю также одним из самых необходимых в реализации, поставленных задач.

Третий этап- создание фирменного стиля. Разберемся, что же такое фирменный стиль. И так, фирменный стиль-это некое визуальное составляющее, который мы можем поместить на упаковках, каких-то подарках для клиентов(например: ручки, брелки, календарики, блокнотики и т.д.). Проще говоря, это наш товарный знак, наш мерчь.

Корпоративный стиль, также является часть лица компании и презентует ее перед потенциальными заказчиками. Значение тут имеет все: шрифт, логотип, фирменный цвет и прочие элементы.

В качестве корпоративного стиля для «И.П. Лапин» было решено для начала выбрать единый цвет. Мы так решили, что это будет синий цвет. Согласно британским исследованиям, цвет является первостепенном в данной работе. Далее прорабатывалась мерч-продукцию. Даже есть несколько компаний которые занимаются изготовлением этой самой мерч-продукции и сейчас мы находимся в режиме «переговоры». Уточню, что экономические затраты на данную реализацию в малой сфере бизнеса оправданно могут быть меньше чем в более крупных и масштабных вариантах.

На данный момент, можно сделать вывод, что именно эти три этапа: официальный сайт, социальные сети и фирменный стиль, являются не заменимыми для бизнеса любой сферы. Если же говорить конкретно о малом деле, то тут стоит учитывать также и то, что тут также должна присутствовать большая экономия финансовых средств и не должно полностью списываться со счетов «сарафанное радио». Сейчас мой проект уже успел доказать, что даже самые первые шаги в продвижении и создание различных интернет-платформ могут принести большую клиентуру и в следствии больший доход даже самому простейшему И.П.

\section{Список источников:}

1. «Основы современного маркетинга». Автор: Шевченко Д.А. : [Жанр: Учебная литература; Год издания: 2019; Издательство: Дашков и К] - (https://avidreaders.ru/book/osnovy-sovremennogo-marketinga.html) ;

2. «Аудитория «ВКонтакте 2021»: [Интернет-источник] (https://vc.ru/vk/279614-auditoriya-vkontakte-2021ezhegodnyy-rost-prodolzhaetsya);

3. «Корпоративная идентичность для менеджеров и маркетологов». Автор: Крылов А.Н.: [Жанр: Учебная литература; Год издания: 2014.] (https://search.rsl.ru/ru/record/01002431141) . 